\title{
PRÁTICAS EDUCATIVAS COM IDOSOS EM UM CENTRO DE REFERÊNCIA DE ASSISTÊNCIA SOCIAL
}

\author{
EDUCATIONAL PRACTICES WITH ELDERLY PEOPLE IN A SO- \\ CIAL ASSISTANCE REFERRAL CENTER
}

\section{PRÁCTICAS EDUCATIVAS CON LOS ADULTOS MAYORES EN UN CENTRO DE REFERENCIA DE ASISTENCIA SOCIAL}

\author{
Jane Mery Richter Voigt ${ }^{1}$ \\ LEANDRO CAMPOS BARROCAS ${ }^{2}$ \\ Silvia Sell Duarte Pillotto ${ }^{3}$
}

${ }^{1}$ Universidade da Região de Joinville (UNIVILLE), Joinville/SC- Brasil

${ }^{2}$ Universidade da Região de Joinville (UNIVILLE), Joinville/SC- Brasil

${ }^{3}$ Universidade da Região de Joinville (UNIVILLE), Joinville/SC- Brasil

RESUmo Ao considerar o envelhecimento da população e a dinamicidade dos mecanismos sociais da contemporaneidade, observamos que há um movimento no tocante à participação mais ativa e contundente dos idosos no mundo produtivo, contribuindo tanto nos papéis sociais como na estrutura familiar e, muitas vezes, em ações educativas não formais. O objetivo do presente artigo é refletir sobre os sentidos e significados atribuídos por idosos às práticas educativas vivenciadas em um Centro de Referência de Assistência Social (CRAS). A pesquisa, de abordagem qualitativa, foi realizada por meio de um Grupo de Discussão com oito idosos frequentadores do CRAS do Jardim Paraíso, na cidade de Joinville (SC). O aporte teórico e metodológico tem como autores Aguiar e Ozella (2006), Freire $(1998 ; 2003 ; 2011)$, Gohn $(2006 ; 2007 ; 2009)$. Os resultados apontam contribuições para as práticas educativas e políticas públicas no sentido de proporcionar uma formação mais humanista, proba e capaz de provocar o sentido de cidadania plena, particularmente nos indivíduos da terceira idade. Para os idosos, o CRAS é um lugar de acolhimento e de convivência, cujas práticas educativas proporcionam um novo sentido para a vida.

Palavras-chave: Políticas públicas; Práticas educativas; Educação não formal; TerceiRA IDADE; SENTIDOS E SIGNIFICADOS. 
Abstract When we consider the aging of the population and the dynamism of the social mechanisms of contemporaneity, we observe that there is a movement regarding the more active and forceful participation of the elderly in the productive world, contributing, both in relation to the social roles, and in the family structure and often in non-formal educational actions. The objective of this article is to reflect on the senses and meanings attributed by the elderly to the educational practices experienced in a Social Assistance Referral Center (CRAS). The qualitative research data was produced through a Discussion Group with eight elderly people attending the CRAS of Jardim Paraíso, in the city of Joinville (SC). The theoretical and methodological contribution was submitted by authors Aguiar and Ozella (2006), Freire (1998; 2003; 2011), Gohn (2006; 2007; 2009). The results may contribute to educational practices and public policies in the sense of providing a more humanistic, probative and capable of provoking a sense of full citizenship, particularly in the elderly. For the elderly, CRAS is a place of welcome and coexistence, whose educational practices provide a new meaning for the lives of those who participate there.

Keywords: Public policies; Educational practices; Non-formal education; Old age; SENSES AND MEANings.

Resumen Al considerar el envejecimiento de la población y al desarrollo de los mecanismos sociales de la contemporaneidad, observamos que hay un movimiento en lo tocante a la participación más activa y contundente de los adultos mayores en el mundo productivo, contribuyendo, tanto con relación a los papeles sociales, como en la estructura familiar y, muchas veces, en acciones educativas no formales. El objetivo del presente artículo es reflexionar sobre los sentidos y significados atribuidos por los adultos mayores a las prácticas educativas vividas en un Centro de Referencia de Asistencia Social (CRAS). La investigación, de abordaje cualitativo, ha sido realizada por intermedio de un Grupo de Discusión con ocho adultos mayores frecuentadores del CRAS del Barrio Jardín Paraíso, en la ciudad de Joinville (SC). El aporte teórico y metodológico tiene como autores Aguiar y Ozella (2006), Freire (1998; 2003; 2011), Gohn (2006; 2007; 2009). Los resultados podrán contribuir para las prácticas educativas y políticas públicas en el sentido de proporcionar una formación más humanista, íntegra y capaz de provocar el sentido de ciudadanía plena, particularmente en los individuos de la tercera edad. Para los adultos mayores el CRAS es un lugar de protección y de convivencia, cuyas prácticas educativas proporcionan un nuevo sentido para la vida de los que allá participan.

Palabras clave: Políticas públicas; Prácticas educativas; Educación no formal; TerceRa EDAD; Sentidos y Significados.

\section{INTRODUÇÃo}

O novo cenário demográfico mundial, decorrente de avanços nas áreas medicinais, ocupacionais e educacionais, apresenta um número de pessoas idosas em ascensão. No Brasil, estima-se que cerca de $11 \%$ da população esteja na terceira idade, o que importa di- 
zer que há uma população idosa de mais de 21 milhões de pessoas no país (BRASIL, 2010).

Com base na Lei n. 8.842, de 4 de janeiro de 1994 (BRASIL, 1994), que implementou a Política Nacional do Idoso, corroborada pela Lei n. 10.741, de 1. . de outubro de 2003 (BRASIL, 2003), considera-se idosa a pessoa com 60 anos ou mais.

Contudo, a rapidez nas mudanças sociais, com maior ênfase nos últimos 20 anos, vem fazendo que o cidadão na terceira idade, de modo geral, tenha maior dificuldade para situar-se nesse contexto, por vezes isolando-se e contribuindo pouco para a sociedade, acabando por se tornar alienado e, com isso, cada vez mais distante do cotidiano, pautado pela velocidade das novidades comportamentais e tecnológicas.

Diante de tal cenário, podem-se levantar as seguintes questões: $\mathrm{O}$ que é necessário para que a pessoa idosa se torne mais engajada e participativa, buscando conhecer seus direitos e deveres, bem como, suas obrigações, fazendo-se respeitar como ser humano, pensante e ativista? Como promover a inclusão social, estímulo ao exercício da cidadania e do bem-estar social do idoso por meio de práticas educativas? Entendemos que a educação pode ser uma forma de investimento na formação de uma terceira idade mais consciente de suas reais capacidades e desenvolvedora de seus talentos. Além disso, a educação pode promover oportunidades para que os idosos aprendam a enfrentar os obstáculos e preconceitos sociais, de modo a acarretar ações que contribuam para a sua qualidade de vida e para o aprimoramento da sua cidadania.

Bons exemplos de práticas educativas ocorrem nos Centros de Referência de Assistência Social (CRAS), órgãos mantidos pela Secretaria de Assistência Social, onde jovens e idosos em situação de risco social recebem orientação educacional, desenvolvem diversas atividades que permitem desde uma maior participação social até a amplitude de saberes e conhecimentos gerais. Essas práticas educativas podem ser pensadas no sentido de uma educação não formal, pois:

[...] na educação não-formal, os espaços educativos localizam-se em territórios que acompanham as trajetórias de vida dos grupos e indivíduos, fora das escolas, em locais informais, locais onde há processos interativos intencionais (a questão da intencionalidade é um elemento importante de diferenciação) (GOHN, 2006, p. 29).

De acordo com a autora, toma-se por finalidade da educação não formal o convite para o conhecimento do cidadão em relação ao mundo no qual vive, bem como, o entendimento acerca das relações sociais que estabelece. Dessa forma, os indivíduos tornam-se aptos e preparados para relacionamentos em sociedade. De acordo com Gohn (2006, p. 30-31), a educação não formal "prepara os cidadãos, educa o ser humano para a civilidade, em oposição à barbárie, ao egoísmo e ao individualismo".

A nossa questão de pesquisa consiste em saber: Quais sentidos e significados são atribuídos pelos idosos às práticas educativas que ocorrem no CRAS? Para isso, realizou-se uma pesquisa no CRAS do bairro Jardim Paraíso, em Joinville (SC), provavelmente a região da cidade que apresenta maior vulnerabilidade social. 
A investigação, de abordagem qualitativa, contou com a participação de oito idosos frequentadores do CRAS, que, por meio de um grupo de discussão, falaram sobre suas experiências de educação não formal no referido espaço. Ouvir os idosos nos auxiliou a conhecer seu dia a dia e a sua forma de vida, suas experiências nas práticas educativas que ocorrem no espaço de educação não formal do CRAS e como elas os afetam.

$\mathrm{O}$ artigo foi organizado de modo a apresentar: aspectos sobre as políticas de assistência social que integram o Sistema Único de Assistência Social, o CRAS e suas práticas educativas; o caminho metodológico da pesquisa, mostrando as etapas e os processos utilizados para a produção e análise dos dados; os núcleos de significação: "o idoso como ser ativo" e "o desenvolvimento do idoso em seus fazeres e saberes".

\section{Políticas Públicas SOCIAIS E SEUS DESDObRaMentos EM PRÁTICAS EDUCATIVAS PARA OS IDOSOS NO CRAS}

Não é nossa intenção trazer um histórico das políticas sociais no Brasil, mas tecer algumas considerações sobre a sua importância para a garantia dos direitos dos cidadãos e, especialmente, para as pessoas na terceira idade. Nesse norte, entre as diversas práticas sociais implementadas pelas políticas públicas nacionais, notadamente no início dos anos 2000, passaram a se destacar aquelas voltadas para assistência social, com a inserção de cidadãos que dependem de qualquer tipo de assistência, ofertadas por meio de políticas e diretrizes previstas na Lei Orgânica da Assistência Social (LOAS). Nos termos do artigo 1. ${ }^{\circ}$ da LOAS, consta que a assistência social é:

\footnotetext{
...direito do cidadão e dever do Estado, é Política de Seguridade Social não contributiva, que provê os mínimos sociais, realizada através de um conjunto integrado de iniciativa pública e da sociedade, para garantir o atendimento às necessidades básicas (BRASIL, 1993).
}

No ano de 2004, a Política Nacional de Assistência Social (PNAS - MDS, 2004) teve sua aprovação com vistas a fortalecer as políticas decorrentes das deliberações da Conferência Nacional da Assistência Social, o que acarretou no ano seguinte na aprovação da Norma Operacional Básica do Sistema Único de Assistência Social (NOB/SUAS - CFESS; SUAS, 2005). Até então, a assistência social não havia sido classificada no Brasil como uma política social do Estado. Com as aprovações de 2004 e 2005, a assistência social deixou de ser mera ação desordenada de governos para se transformar em política social de Estado.

Ainda quanto ao texto da PNAS (MDS, 2004), a assistência social deve dar primazia à atenção às famílias de baixa renda e seus membros, a partir do seu território de vivência, com prioridade àqueles com registros de fragilidades, vulnerabilidades e presença de vitimizações entre seus membros. Logo, tendo em vista os objetivos de propor e implementar a gestão da assistência social mediante o Sistema Único de Assistência Social (SUAS), atendendo ao princípio da integralização das ações assistenciais previsto na LOAS, foi possível 
desenvolver uma relação mais dinâmica entre programas, projetos, serviços e benefícios de assistência, atingindo, assim, de forma mais abrangente a sociedade relacionada ao sistema.

Sposati (2006, p. 111) explica que o SUAS não deve ser confundido com uma política nem tampouco com um programa assistencial, uma vez que não se trata de:

[...] um programa, mas uma nova ordenação da gestão da assistência social como política pública. [...] é uma forma pactuada que refere o processo de gestão da assistência social, antes de iniciativa isolada de cada ente federativo, a uma compreensão política unificada dos três entes federativos quanto ao seu conteúdo (serviços e benefícios) que competem a um órgão público afiançar ao cidadão.

A proteção social de assistência social ofertada pelo SUAS é dividida em dois tipos: a básica e a especial. De acordo com a Secretaria Especial do Desenvolvimento Social (SEDS, 2015):

\begin{abstract}
A [...] Proteção Social Básica [é] destinada à prevenção de riscos sociais e pessoais, por meio da oferta de programas, projetos, serviços e benefícios a indivíduos e famílias em situação de vulnerabilidade social. A [...] Proteção Social Especial [é] destinada a famílias e indivíduos que já se encontram em situação de risco e que tiveram seus direitos violados por ocorrência de abandono, maus-tratos, abuso sexual, uso de drogas, entre outros.
\end{abstract}

Uma das unidades públicas das políticas de assistência social que integram o SUAS é o Centro de Referência de Assistência Social (CRAS), localizado em áreas com maiores índices de vulnerabilidade e risco social. O CRAS presta serviços e programas socioassistenciais de proteção social básica, ou seja, atende famílias e indivíduos em situação de pobreza, privação (a exemplo, a ausência de renda, precário ou nulo acesso aos serviços públicos), discriminação (de gênero, de etnia, entre outras). Além disso, atende a pessoas de pouca inserção social e fragilizadas em seus vínculos afetivos e em situações de abandono pelas famílias.

Ao atender às necessidades específicas de assistência social de cada região, o CRAS, entre suas atribuições, oferece atividades educacionais, desenvolvendo práticas educativas que podem ser caracterizadas como educação não formal. Em espaços formais, a educação tem objetivos claros e específicos e é representada principalmente pelas escolas e universidades (GADOTTI, 2006). Já em espaços de educação não formal, de acordo com Gohn (2007), a educação está muito relacionada à ideia de cultura, pois os programas e as atividades são propostos de maneira a respeitar o ritmo de cada turma; assim é mais difusa, menos hierárquica e menos burocrática que a educação formal. Os aspectos apontados por Gohn (2007) são contemplados na proposta do CRAS. Por isso, as práticas educativas que lá ocorrem correspondem à educação não formal.

Machado (2008) também sustenta que a educação não formal não exige ou dispõe de uma estruturação rígida nem tampouco sistematizada. A educação não formal ocorre em 
espaços coletivos de troca de saberes, vivências e experiências; fica à margem do organograma do sistema educativo graduado e hierarquizado. $\mathrm{O}$ aprendizado acontece de forma que os indivíduos participem voluntariamente dos grupos.

Na mesma linha, Silva, Souza Neto e Moura (2009) apontam que, de modo diferente da educação formal, que possui limitações para promover inclusões sociais em curto espaço de tempo, as práticas proporcionadas pela educação não formal acabam por oferecer a elevação ou a recuperação da autoestima e o desenvolvimento da consciência política e social de cada indivíduo.

Dada sua natureza específica de espaço de educação não formal, o CRAS desenvolve suas atividades por meio de atos e ações coordenados por profissionais de diversas áreas de atuação, com igual variedade de formação e ocupação social, o que preceitua a chamada pedagogia social. Nos termos de Díaz (2006, p. 92), trata-se de:

\begin{abstract}
...uma ciência pedagógica, de caráter teórico-prático, que se refere à socialização do sujeito, tanto a partir de uma perspectiva normalizada como de situações especiais (inadaptação social), assim como aos aspectos educativos do trabalho social. Implica o conhecimento e a ação sobre os seres humanos, em situação normalizada como em situação de conflito ou necessidade. O conceito de pedagogia social mais generalizado é o que faz referência à ciência da educação social das pessoas e grupos, por um lado, e, por outro, como ajuda, a partir de uma vertente educativa, às necessidades humanas que convocam o trabalho social, assim como o estudo da inadaptação social.
\end{abstract}

Gohn (2009, p. 33) salienta o papel e a função do educador social, destacando a amplitude e a importância de sua atuação, uma vez que:

...o diálogo - tematizado - não é um simples papo ou conversa jogada fora, é sempre o fio condutor da formação. Mas há metodologias que supõem fundamentos teóricos e ações práticas - atividades, etapas, métodos, ferramentas, instrumentos etc. O espontâneo tem lugar na criação, mas ele não é o elemento dominante no trabalho do Educador Social, pois o seu trabalho deve ter princípios, métodos e metodologias de trabalho.

Cumpre, portanto, ao educador social em uma unidade de educação não formal como o CRAS adentrar aos poucos na realidade do participante, do educando, de modo a fazer que este se sinta importante, valorizado, ativo e partícipe. Dalla Vale (2011, p. 144) afiança:

Como primeira recomendação, é preciso compor uma proposta pedagógica adequada a esse grupo etário tão distinto entre si, mas tão diferenciado do grupo de crianças em idade de alfabetização. Cabe, então, caracterizar o perfil do aluno dessa modalidade de ensino.

Freire (1998, p. 36) diz que "ensinar exige vigilância do bom senso", o que, no caso da educação não formal para idosos, faz ainda mais sentido, haja vista que o educador 
social não deve ignorar a bagagem de vida trazida pelo educando. Como afirma Freire (2011, p. 95-96):

\begin{abstract}
O educador já não é o que apenas educa, mas que, enquanto educa, é educado, em diálogo com o educando que, ao ser educado, também educa. Ambos, assim, se tornam sujeitos do processo em que crescem juntos e em que os argumentos de autoridade já não valem. Em que, para ser-se, funcionalmente, autoridade, se necessita de estar sendo com as liberdades e não contra elas.
\end{abstract}

Nessa perspectiva, as ações do educador serão mais simples e de fácil apropriação se ele tiver a sutileza, a delicadeza de saber afetar, de se inserir no contexto de vida do idoso, partilhando de suas experiências, ansiedades, anseios e temores.

Nesse sentido, com o apoio e com a sutileza do educador social, o idoso:

[...] se vê compelido a reconstituir seus vínculos, a buscar formas de viver seu cotidiano, sem contar mais com as redes de apoio familiar. O idoso pode ser forçado a aprender a conviver com aqueles totalmente desconhecidos, após longa trajetória de vida convivendo com aqueles com quem mantinha laços de amizade e consanguinidade, deixando para trás seu estilo de vida pessoal e de viver seu cotidiano (BESSA; SILVA, 2008, p. 259).

Assim, as práticas educativas empregadas nos espaços não formais de educação que envolvem os idosos, especialmente os que estão em situação de vulnerabilidade, podem potencializar o senso de consciência e de cidadania. As práticas utilizadas na educação não formal se mostram eficazes em torno de um processo de dimensões que ampliam seus objetivos na transformação da sociedade, com a inclusão de todos os cidadãos.

\title{
O CAMINHO METODOLÓGICO
}

Para evidenciar os sentidos e significados das práticas educativas vivenciadas pelos idosos no CRAS, fez-se necessária uma pesquisa de abordagem qualitativa que pudesse alcançar mais do que questões puramente imediatas e numericamente tabuláveis. Vale ressaltar que essa abordagem de pesquisa também:

...visa a compreender a lógica interna de grupos, instituições e atores quanto a (a) valores culturais e representações sobre sua história e temas específicos; (b) relações entre indivíduos, instituições e movimentos sociais; (c) processos históricos, sociais e de implementação de políticas públicas e sociais (MINAYO, 2007, p. 23).

A pesquisa também se pautou numa perspectiva histórico-social, cuja referência básica de análise é a historicidade das experiências humanas. No momento em que recuperamos a história do sujeito, podemos compreender como ele é determinado, pois o social 
constitui o sujeito (PINO, 2002). Portanto, para apreender sentidos e significados, é importante evidenciar, sobretudo, as realidades dos participantes da pesquisa, seus afazeres, suas rotinas, sabendo que há um dinamismo entre essas realidades e o ambiente no qual eles estão inseridos.

O lócus da pesquisa foi o CRAS do bairro Jardim Paraíso, em Joinville (SC), localizado em uma das regiões da cidade de maior vulnerabilidade social. A instituição oferece aos idosos cadastrados diversas atividades e práticas educativas orientadas por um educador social, cuja ação pedagógica está pautada no diálogo e na democracia, desmistificando a ideia autoritária de hierarquia entre aluno e professor.

As atividades com os idosos (16 ao total) são realizadas semanalmente no CRAS $^{1}$ e acontecem em grupo. Nesses encontros são oferecidas atividades artísticas, culturais, de lazer e esportivas, entre outras, adequadas aos idosos. Elas visam contribuir para a melhoria da qualidade de vida das pessoas idosas, tendo como foco o processo de envelhecimento ativo e saudável, assim como o desenvolvimento da autonomia e da sociabilidade.

Dos 16 idosos, foram selecionados oito, que eram os mais assíduos nas atividades desenvolvidas no $\mathrm{CRAS}^{2}$ e que se dispuseram a conversar sobre as práticas educativas feitas nos encontros semanais. Os idosos selecionados assinaram o termo de consentimento livre e esclarecido (TCLE), conforme a Resolução Conselho Nacional de Saúde (CNS 466/2012). Todos os selecionados se mostraram interessados em participar da presente pesquisa, que foi efetuada no próprio CRAS Jardim Paraíso, em uma sala preparada para o grupo de discussão.

O grupo de discussão permitiu documentar experiências coletivas oriundas da interação entre os participantes, bem como, as suas características sociais. "O objetivo maior do grupo de discussão é a obtenção de dados que possibilitem a análise do contexto ou do meio social dos entrevistados, assim como de suas visões de mundo ou representações coletivas" (WELLER, 2013, p. 56).

De acordo com Weller (2013) e com base na pesquisa realizada por Silva (2015), a organização do grupo de discussão levou em conta os seguintes aspectos: a) a escolha do espaço, uma vez que pode trazer uma carga simbólica que, por vezes, pode influenciar no resultado do estudo. Por essa razão, o grupo de discussão com os idosos ocorreu em uma sala no próprio CRAS, na qual os idosos puderam se acomodar ao redor de uma mesa para conversar; b) o tempo de duração da atividade, que não deve ser muito extenso, para evitar que a fadiga influencie as falas, reprima manifestações ou ainda gere a perda do interesse de participantes. Portanto, o grupo de discussão com os idosos durou em torno de $80 \mathrm{mi}-$ nutos; c) a formação do grupo, que de acordo com a literatura não deve ser inferior a sete nem tampouco ser superior a dez. Assim, o número de oito idosos está de acordo com as recomendações dos autores; d) a seleção e escolha dos participantes, que se deu por meio de critérios como assiduidade, disposição para participar e envolvimento nas atividades

\footnotetext{
As atividades estão vinculadas ao Serviço de Convivência e Fortalecimento de Vínculos (SCFV), que é um serviço de Proteção Social Básica do SUAS.

2 Informação fornecida pela equipe gestora do CRAS Jardim Paraíso.
} 
do CRAS; e) o moderador, que nesta pesquisa foram os próprios pesquisadores, que expuseram aos participantes o objetivo da investigação e os instigaram à fala, sem, contudo, opinar ou manifestar-se conclusivamente, valorizando assim o discurso livre e espontâneo dos idosos.

O encontro do grupo de discussão com os idosos, realizado no dia 6 de setembro de 2017, nas dependências do CRAS Jardim Paraíso, foi gravado em áudio. O material produzido pelas gravações em áudio foi transcrito e analisado, permitindo revelar sentidos e significados atribuídos às atividades no CRAS Jardim Paraíso. Para preservar a identidade dos participantes, os próprios idosos escolheram os nomes usados nas análises.

Para analisar os dados, recorreu-se aos Núcleos de Significação, de Aguiar e Ozella (2006). Nessa proposta, a apreensão dos sentidos não revela uma única resposta, coerente, definida, completa, mas expressões do sujeito algumas vezes contraditórias e parciais e que apresentam indicadores das formas de ser e pensar do sujeito e dos processos por ele vividos.

Após a transcrição do material gravado no grupo de discussão, fez-se a leitura flutuante, a qual permitiu destacar e organizar o que Aguiar e Ozella (2006) chamam de pré-indicadores: palavras com significado que se destacam no momento empírico da pesquisa, na fala do sujeito. Tal leitura é realizada diversas vezes, para que os pesquisadores se familiarizem com o material e aos poucos se apropriem dele.

Após nova leitura das transcrições do grupo de discussão, reuniram-se os pré-indicadores, o que permitiu que novos olhares surgissem, seja pela proximidade das falas, das opiniões e do discurso como um todo, pelas expressões e manifestações diversas, seja pelas contradições e posicionamentos divergentes. Um novo bloco se formou, o qual passamos a chamar de indicadores. Também é importante considerar que "[...] os indicadores só adquirem algum significado se inseridos e articulados na totalidade dos conteúdos temáticos apresentados, ou seja, na totalidade das expressões do sujeito" (AGUIAR; OZELLA, 2006, p. 13).

Da aglutinação e da reunião desses fragmentos, colheu-se o terceiro e definitivo conjunto, denominado de núcleos de significação, por meio dos quais a análise dos dados teve como objetivos identificar e relatar os sentidos e os significados das práticas educativas vivenciadas pelos idosos no CRAS. Os núcleos de significação expressam o movimento de abstração que, sem dúvida, contém o empírico, permitindo o caminho em direção ao concreto. Buscou-se, com base no que foi dito pelos idosos, entender aquilo que não foi dito: apreender a sua fala interior, o seu pensamento, o processo (e as contradições presentes nesse processo) de constituição dos sentidos que cada um atribui às práticas educativas das quais participa no CRAS Jardim Paraíso.

\section{O NÚCLEO DE SIGNIFICAÇÃO "O IDOSO COMO SER ATIVO"}

O núcleo de significação "o idoso como ser ativo" decorreu das manifestações da relação de amizade que os idosos construíram com os demais participantes durante as reuniões do CRAS, além dos novos conhecimentos, confrontando tais sensações positivas com a ideia de solidão, de ociosidade, desocupação e abandono. 
Em seu discurso, D. Aládia frisa, desde o primeiro momento, que uma das principais motivações geradas pelas práticas desenvolvidas no CRAS é a amizade cultivada entre os idosos participantes e o aprendizado.

Eu penso que o CRAS é ótimo, porque a gente não fica sozinha dentro de casa, está aqui sempre aprendendo alguma coisa nova, tendo muitas amizades. $O$ que mais importa para a gente é a amizade, sempre estamos conhecendo gente (D. Aládia, grupo de discussão, set./2017).

Ela enfatiza que conhecer pessoas the permite estar em constante aprendizado, pois, segundo ela, "todos temos sempre o que aprender e o que ensinar" (D. Aládia, grupo de discussão, set./2017). Diante dessa fala, podemos refletir sobre a relevância do CRAS como espaço de educação não formal:

A maior importância da educação não-formal está na possibilidade de criação de novos conhecimentos, ou seja, a criatividade humana passa pela educação não-formal. $\mathrm{O}$ agir comunicativo dos indivíduos, voltado para o entendimento dos fatos e fenômenos sociais cotidianos, baseia-se em convicções práticas, muitas delas advindas da moral, elaboradas a partir das experiências anteriores, segundo as tradições culturais e as condições histórico-sociais de determinado tempo e lugar (GOHN, 2006, p. 104).

Na mesma linha de raciocínio, porém na contramão do sentido positivo dado às amizades construídas, aparecem o medo e a tristeza com a solidão, como ficar em casa sem ter o que fazer. Em suas narrativas, ficou claro o receio de não ter o seu tempo ocupado, em ficar em casa sem distração, com o pensamento em coisas não produtivas ou que não tragam retorno.

O Sr. João manifestou-se no grupo de discussão com um tom de voz mansa e demonstrando não ter pressa alguma; passou uma serenidade, no mínimo, intrigante. Fica evidente que suas origens o marcaram profundamente, remetendo a uma vida sem a agitação dos grandes centros ou sem a pressa do cotidiano moderno.

Amparado na relação pessoal com os demais membros do grupo, o Sr. João nos informou que ali, naquele espaço, tem conhecidos que lhe permitem um convívio social agradável, que lhe traz divertimento. Aduz que a amizade possibilita a conversa e facilita o diálogo, como se conversar com um desconhecido fosse mais complicado do que com alguém que já faça parte do seu ciclo social.

Eu, pra mim, é a mesma coisa que ela falou, eu, pra mim, é um divertimento, é uma coisa que eu venho para se encontrar com os conhecidos, né?!, Às vezes a gente chega aqui e não conhece alguém e daí já fica conhecendo, isso é muito bom, porque a nossa turma de amigos vai sempre crescendo (Sr. João, grupo de discussão, set./2017).

Sr. João sustenta que, quando um amigo deixa de frequentar o CRAS e eles se encontram pelas ruas, "já é motivo para uma prosa", para saber o que cada um anda fazendo, para 
retomar o relacionamento, resgatando um convívio. A ideia inicial que circula em torno de quem o participante chama de conhecido poucos instantes depois já é vislumbrada na questão da amizade, já citada por D. Aládia, pois demonstra que o vínculo criado é levado para fora das instalações do CRAS, se torna amplo: "Até mesmo as pessoas que param de vir, quando eu vejo na rua, já é motivo para uma prosa, para saber o que está fazendo" (Sr. João, grupo de discussão, set./2017).

Lima (2005, p. 18) traz alguns elementos para que possamos pensar sobre a importância dos vínculos estabelecidos nas atividades realizadas com idosos:

\begin{abstract}
A atividade do fazer humano é essencial ao equilíbrio físico, psicoemocional e social do idoso, na medida em que favorece o continuar vivendo, mesmo que fatos negativos possam interpor-se ao processo de envelhecimento. Estimula-o a continuar a fazer planos, estabelecer os contatos sociais, tornando-o ativo, participante de sua comunidade, autônomo, aos olhos da sociedade, um velho sem o estigma de velho.
\end{abstract}

Em seu discurso, o Sr. Antonio, com 63 anos de idade e aparentando raciocínio rápido e uma condição física privilegiada, se comparada aos demais integrantes (principalmente quanto aos homens), embora já tenha alcançado idade para ser considerado idoso (conceito legal), não se percebe como tal:

Eu não tenho vindo muito, mas, quando eu venho, me sinto muito bem, fiz muitos amigos aqui. Encontro as pessoas na rua, os colegas da gente [...]. Então, além da amizade, tem a conversa, o sentimento de eu saber entender as pessoas de mais idade, porque eu já sou meio idoso, né, mas nunca tinha participado assim, com outras pessoas idosas de nada desse tipo (Sr. Antonio, grupo de discussão, set./2017).

Sr. Antonio ainda tem dificuldades de se acostumar com a vida urbana. Tendo morado em sítio por toda a vida, sente os efeitos característicos da vida urbana: o distanciamento existente entre as pessoas, pois, embora estejam muito próximas fisicamente, há um distanciamento entre elas. A correria diária, atrelada à falta de tempo para tudo, não permite "prosear com os amigos", como diz o Sr. Antonio, visitar as pessoas e realmente se importar com elas.

Nota-se que o fantasma da solidão e do ócio é um pré-indicador facilmente encontrado nas narrativas. Os idosos apontaram que, se não fosse o CRAS, ficariam em casa sem ter o que fazer, sem distração, sem ocupação e sem desenvolvimento algum.

Eu só não venho para cá mesmo se eu tô doente, ou se eu não posso mesmo, se eu não tô em casa por algum motivo... Se eu tô em casa, é de certeza que eu venho para cá, porque não tem o que, não tem como pegar o conhecimento com outras pessoas se você fica em casa olhando pra ontem (Sr. João, grupo de discussão, set./2017). 
Diante das manifestações aqui expostas dos idosos, da constatação do envelhecimento da população mundial, em especial da brasileira, diversos "novos" problemas vão sendo encarados pela população idosa. As aspas na palavra novos foram propositalmente colocadas para evidenciar que o novo é apenas o fato de a população estar envelhecendo cada vez mais. Porém, vários problemas já eram enfrentados e conhecidos pelos idosos mesmo antes do fator envelhecimento.

Um dos mais comuns pesadelos que afligem os idosos está relacionado à solidão, ao abandono. A solidão provoca um sentimento de vazio interior, que pode estar presente no ser humano nas diferentes fases da vida, e tende a ser mais frequente com o envelhecimento. Fatores psicológicos e sociais parecem estar relacionados com o seu surgimento, como a depressão, o luto, o isolamento social e o abandono. Assim, diante do aumento da expectativa de vida, é necessário que:

...as preocupações giram [girem] em torno de vários aspectos, inclusive de que
não adianta ter tempo livre, não adianta viver mais, se não forem criadas e
oferecidas as condições para viver bem esse tempo que têm os idosos. É nes-
se sentido que a sociedade precisa contabilizar uma outra velhice, que institui
demandas que precisam ser socialmente incorporadas; uma velhice capaz de
oferecer um rico repertório de habilidades, de conhecimentos e de experiências;
uma velhice que saia do isolamento sócio-cultural a que ainda é submetida em
diferentes espaços geográficos; que saia da pobreza educativa a que ainda vive
submetida parte significativa dela (D'ALENCAR, 2002, p. 64).

As variadas situações que levam à solidão e ao abandono usualmente são provocadas e decorrentes da condição de fragilidade que é natural do idoso. Da análise dos cadastros no CRAS dos participantes da pesquisa, fica evidente que a maioria não tem convívio direto e corriqueiro com seus familiares mais próximos. Assim, é natural que venham a depender de outras pessoas, seja pela perda da autonomia e da independência, seja pelo distanciamento e esfriamento dos vínculos afetivos que mantinham. Ou ainda, pela conduta do grupo de relações ou até mesmo a ausência deste, o que acaba por impedir que o indivíduo viva e conviva de forma plena e de manter-se inserido no convívio familiar, no grupo e nas atividades culturais.

\section{O NÚCLEO DE SIGNIFICAÇÃO "O DESENVOLVIMENTO DO IDOSO EM SEUS FAZERES E SABERES"}

A descoberta e o encanto com o novo chamam muita atenção nos relatos dos idosos. Talvez pelo fato de esperar-se que um cidadão com certa idade, com tanta experiência, já tenha percorrido um caminho que foi capaz de mostrar-lhe de tudo, de proporcionar-lhe vivências diversas. Porém, o que se destaca é justamente o inverso! Situações como ir a um recital são citadas com tamanha alegria, com tanta ênfase que chega a ser inusitado descrevê-las como algo capaz de emocionar e tocar pessoas com tamanha bagagem.

Comunicações | Piracicaba $\mid$ v. $26 \mid$ n. $23 \mid$ p. 217-235| set.-dez. 2019 
D. Aládia narra com entusiasmo uma das experiências que o CRAS the proporcionou, citando a organização de um passeio até o teatro em uma cidade vizinha, onde assistiram a uma apresentação musical:

Coisa mais linda mesmo!!! Eu nunca tinha visto nada como aquilo, eu nunca que me esqueço aquilo lá, parecia um palácio, um espetáculo da natureza! Já andei por aí, por tudo que é canto, por esse mundo inteiro e nunca, mas nunca que eu vi um negócio tão lindo como aquilo. Fiquei muito feliz com aquele passeio e de ver aquilo lá, foi como ir na casa de um rei. Me impressionou muito aquilo... (D. Aládia, grupo de discussão, set./2017).

A simplicidade, característica tão acentuada na vida dos idosos que integraram a pesquisa, retrata o quanto eles se sentem saciados com passeios e com visitas a lugares que não fazem parte do seu cotidiano. De fato, o teatro citado por D. Aládia destoa dos demais espaços daquela região, bem como, poderia facilmente ser usado como referência, tanto pela arquitetura quanto pela modernidade de suas instalações. O seu encanto com aquela novidade - considerando que ela tem 82 anos de idade, ou seja, possui uma boa estrada já percorrida na vida - demonstrou que o idoso tem vontade de continuar aprendendo sempre.

Da mesma forma, D. Rosa aponta-nos como é importante e encorajador expor sua voz no coletivo. Na interação, D. Rosa revisitou suas memórias de infância e reaprendeu com os demais participantes do grupo a cantar, agora com uma nova significação - a alegria de estar junto, de compartilhar e criar algo que havia deixado no passado.

Achava que nunca ia segurar num pincel e pintar. Quando fiz isso pela primeira vez, me senti uma artista mesmo. E quando cantamos então... eu, que não cantava desde a infância e achava minha voz feinha, mudei de ideia, porque junto com as outras vozes ficou tão linda! (D. Rosa, grupo de discussão, set./2017).

Outro aspecto que se destaca foi observado na fala da D. Iracema, quando cita a importância do CRAS:

Então, pra mim, no que eu entendo, o CRAS [...] é muito importante, porque é que nem um pedaço da Prefeitura... porque, ao invés de eu ira lá no INPS para resolver meus problemas, dai eu venho aqui... porque eu moro num bairro, dai eu venho aqui. Em vez de eu ter que pegar dois ônibus e ir no centro, eu venho aqui e resolvo com as pessoas daqui, que sabem tudo o que eu preciso resolver. E só se não tiver como ser resolvido aqui é que elas me dizem como eu tenho que fazer para resolver (D. Iracema, grupo de discussão, set./2017).

Dessa forma, o CRAS proporciona aos idosos que o frequentam a capacidade de aprender com as práticas educativas, a exemplo: habilidades artísticas (desenho, pintura, modelagem), artesanais (bordado, customização, tecelagem), musicais (audição, musicalização), artes cênicas (dança, teatro, expressão corporal), além de informações sobre o Estatuto do Idoso (direitos civis, sociais, políticos). Esses fazeres e saberes são apreendidos nas 
interações e no modo de empregar suas experiências em prol de seu bem-estar, o que está relacionado aos conceitos apresentados por Neri, Yassuda e Cachioni (2004, p. 178), naquilo que os autores chamam de "velhice bem-sucedida", uma vez que os participantes citados estão empregando recursos internos próprios aplicados ao modo de vida de cada um, para que possam conduzir suas vivências em direção ao modelo de satisfação na plenitude.

Outra importante distinção que se extrai da narrativa é apontada na fala de D. Rosa, ao dizer que o CRAS não seria um local para simplesmente passar o tempo ou ocupar o tempo, dando nítida impressão que outras experiências ou conhecimento acerca de outras atividades envolvendo os idosos fossem para tal finalidade (matar o tempo).

O entusiasmo com o qual os idosos desempenham suas atividades é cristalino. Ao mostrar o bordado que com esmero fazia, D. Aládia apresentava um brilho nos olhos e um sorriso que não cabem em palavras. Diante disso, pensamos no que afirma Vigotski (2009), ao dizer que os sentidos das palavras não cabem em si. O gesto de empunhar o tecido e os olhos reluzentes eram capazes de expressar mais do que a conjunção de letras formadoras de verbetes:

\footnotetext{
Sim, porque não é como se se tivesse só cuidando de passar o tempo, o Sr. olha o tanto de coisa que a gente aprende aqui [...] não tem uma semana que a gente chega aqui e vai embora sem ter aprendido coisas novas, sem ter visto as amigas e conhecido um monte de coisa... é pintura, desenho, esse bordado mesmo que estamos fazendo hoje, olha só como é bom fazer essas coisas (D. Aládia, grupo de discussão, set./2017).
}

Partindo para a análise de outro indicador da pesquisa, surgiu no discurso, com especial atenção e carinho, a figura do educador social. O fascínio que os idosos demonstram pelas educadoras que os atendem é impressionante. Muito mais do que um serviço, fica transparente a relação galgada em sedimentados blocos de confiança, carinho, compaixão e cumplicidade.

Como muito bem destacou D. Aládia, não se trata de fazer o tempo passar. As técnicas de pintura, desenho, recorte, costura, bordado, apliques, bem como, as cantigas e todas as demais atividades que desempenham, giram em torno de um universo, cercado de sorrisos, gargalhadas, descontração e harmonia, cuja mediação é realizada pela educadora social que os acompanha.

D. Emília, acerca da educadora social, conta:

Eu acho que elas são muito bem preparadas e estão sempre alegres [risos], elas são muito alegres! Porque não tem nada que a gente pergunta que eles não explicam, mas é sempre assim, tudo que a gente precisa eles dão um jeito de explicar e de ensinar. Se está fazendo alguma coisa errada, eles mostram como que deve de ser feito e pronto! Eles conhecem os nossos direitos! Elas passam muita coisa para a gente, elas mudaram a vida da gente (D. Emília, grupo de discussão, set./2017).

Fato é que a legislação assegura os direitos fundamentais do idoso, seja nos âmbitos social, físico, mental, como também em alguns aspectos na questão financeira, porém nem 
sempre os direitos são divulgados e conhecidos. Diante da fala da D. Emília, observa-se a importância do papel dos educadores sociais na instrução sobre os direitos dos idosos.

Os relatos do Sr. Nelso e do Sr. Mário também revelam que as atividades do CRAS os auxiliam a estar inseridos na sociedade:

Eu venho pra cá para ver as coisas como são feitas, porque tem muita coisa que a gente vê e não sabe o que é, não tem como saber. Parece que a gente fica mais... mais inteligente [risos], ué, e não é?! Vai me dizer que não é assim mesmo? (Sr. Nelso, grupo de discussão, set./2017).

A gente até vai passear, ouvir músicas lá no Belas, coisa linda, né? Nunca tinha visto assim ao vivo, os músico tocando. Via só na TV e agora posso dizer que vi de outro jeito, né? É bom por demais... (Sr. Mário, grupo de discussão, set./2017).

As práticas educativas devem contemplar a construção integral do ser humano e, nas atividades desenvolvidas no CRAS, todo o empenho e a adoção de cuidados no desenvolvimento de práticas não formais de ensino mantêm estreita relação com o contexto de vida do idoso, contribuindo para a manutenção de uma sociedade mais justa.

Como bem dizem Romans, Petrus e Trilla (2003, p. 128), o educador social contribui para o processo educativo no meio em que está inserido:

\begin{abstract}
Lembremos que o exercício profissional do educador social se baseia na orientação, na melhoria, no enriquecimento e nas contribuições para os processos educativos dos demais, quer dizer, fundamentalmente sua atividade profissional repousa nas suas interações com os usuários e usuárias dos serviços, aspectos que requerem não apenas o conhecimento de técnicas, recursos e métodos, como também, e principalmente, a capacidade de empatia, escuta e resposta em sua relação profissional.
\end{abstract}

A discussão instaurada aponta para o sentido de que o educador social deve partir sua ação do lugar onde o educando está, considerando sua forma de vida, seus hábitos, enfim, o seu universo, com atividades que não soem absurdas ou descabidas, ainda que se inove e se produzam atividades distantes das realidades dos idosos. Nesse norte, de acordo com Gohn (2009, p. 34):

...o Educador Social atua em uma comunidade nos marcos de uma proposta socioeducativa, de produção de saberes a partir da tradução de culturas locais existentes, e da reconstrução e ressignificação de alguns eixos valorativos, tematizados segundo o que existe, em confronto com o novo que se incorpora.

O profissional educador social vem ganhando destaque nos movimentos que envolvem práticas educativas não formais no Brasil, como as desenvolvidas no CRAS. Assim, tão importante quanto o desenvolvimento e a disseminação das atividades exercidas pelo 
profissional da Educação Social, apresentam-se, como grande desafio, o reconhecimento e a regulamentação de sua atividade como profissão, pois a quantidade de cidadãos direta e indiretamente engajados em processos educativos, seja na qualidade de mediadores, seja de receptores, é de grande relevância nos diferentes núcleos, grupos e classes.

\section{CONSIDERAÇões FINAIS}

Considerando o objetivo deste artigo, que consiste em refletir sobre os sentidos e significados atribuídos por idosos às práticas educativas vivenciadas em um CRAS, pode-se inferir que, ao se sentirem resgatados e acolhidos no que tange ao convívio social e à atividades culturais, os idosos revigoraram as energias, descobriram novos fazeres e saberes, além de manterem outros tantos em funcionamento, o que gera a sensação de bem-estar e provoca o interesse nas relações.

Pesquisadores da área do envelhecimento, quando se referem a estudos sobre a importância do suporte social na qualidade de vida, no bem-estar e saúde do idoso, ressaltam que o convívio com amigos, vizinhos, a comunidade e grupos de maneira geral possibilita um melhor enfrentamento de situações difíceis e também em relação ao sentimento de abandono e solidão. Além disso, com base nas falas dos idosos participantes desta pesquisa, o convívio nas atividades do CRAS fortaleceu a autoestima, a autoconfiança e aumentou a sensação de domínio e competência diante das dificuldades, o que pode possibilitar um envelhecimento bem-sucedido.

Freire (2003), em suas reflexões sobre a educação de adultos e o papel do professor/ educador social, ao abordar o amor pelo saber, cita o respeito como condição básica para que o educador venha a desempenhar a função de ensinar, classificando-o como uma conduta que não permite uma relação de pouco caso com o conteúdo a ser ensinado.

No contexto da pesquisa realizada, e com base no que diz Freire (2003), revela-se a importância do educador social nas práticas educativas desenvolvidas no CRAS, pois, por meio de suas atividades, percebe as potencialidades dos idosos, dando-lhes a oportunidade de vivenciar seus "fazeres" e "saberes".

Assim, mais do que nunca, é necessário que a sociedade e o Estado, por intermédio de políticas públicas, reconheçam que os idosos que vivem neste início do século 21 têm muitos desafios, dadas as rápidas mudanças que acontecem. Os idosos, em particular, não só precisam da adaptação, como também de reconhecimento como sujeitos de direito, inseridos numa sociedade em que buscam seu espaço e reconhecimento. Oferecer condições para contribuir nesse processo será o grande desafio da educação de idosos, sobretudo no CRAS, enquanto política social. 


\section{REFERÊNCIAS}

AGUIAR, Wanda Maria Junqueira; OZELLA, Sergio. Núcleos de significação como instrumento para a apreensão da constituição dos sentidos. Psicologia: Ciência e Profissão, v. 26, n. 2, p. 222-245, 2006.

BESSA, Maria Eliana P.; SILVA, Maria Josefina da. Motivações para o ingresso dos idosos em instituições de longa permanência e processos adaptativos: um estudo de caso. Texto $\boldsymbol{\&}$ Contexto - Enfermagem, v. 17, n. 2, p. 258-265, 2008.

BRASIL. Lei n. 8.742, de 7 de dezembro de 1993 (Lei Orgânica da Assistência Social). Dispõe sobre a organização da Assistência Social e dá outras providências. Brasília, 1993.

. Lei. n. 8.842, de 4 de janeiro de 1994. Dispõe sobre a Política Nacional do Idoso, cria o Conselho Nacional do Idoso e dá outras providências. Brasília, 1994.

. Lei n. 10.741, de 1. ${ }^{\circ}$ de outubro de 2003 (Estatuto do Idoso). Dispõe sobre a Política Nacional do Idoso e dá outras providências. Brasília, 2003.

CFESS - CONSELHO FEDERAL DE SERVIÇO SOCIAL; SUAS - SISTEMA ÚNICO DE ASSISTÊNCIA SOCIAL. Norma operacional básica. Brasília, 2005.

D'ALENCAR, Raimunda Silva. Ensinar a viver, ensinar a envelhecer: desafios para a educação de idosos. Estudos Interdisciplinares sobre o Envelhecimento, v. 4, p. 61-83, 2002.

DALLA VALLE, Luciana de Luca. Metodologia de alfabetização, 2. ed. Curitiba: IBPEX, 2011.

DÍAZ, Andrés Soriano. Uma aproximação à pedagogia social. Revista Lusófana de Educação, v. 7, p. 91-104, 2006.

FREIRE, Paulo. Cartas a Cristina: reflexões sobre minha vida e minha práxis. São Paulo: Unesp, 2003.

. Pedagogia da autonomia: saberes necessários à prática educativa. São Paulo: Paz e Terra, 1998.

. Pedagogia do oprimido, 50. ed. São Paulo: Paz e Terra, 2011. 
GADOTTI, Moacir. Concepção dialética da educação: um estudo introdutório, 15. ed. São Paulo: Cortez, 2006.

GOHN, Maria da Glória. Educação não-formal, participação da sociedade civil e estruturas colegiadas nas escolas. Revista Ensaio - Avaliação e Políticas Públicas em Educação, v. 14, n. 50, p. 11-25, 2006.

. Educação não-formal e o papel do educador(a) social. Revista Meta: Avaliação, v. 1, n. 1, p. 28-43, 2009.

. Não-fronteiras: universo da educação não-formal. São Paulo: Itaú Cultural, 2007. (Rumos Educação, Cultura e Arte, 3.)

IBGE - INSTITUTO BRASILEIRO DE GEOGRAFIA E ESTATÍSTICA. Censo demográfico 2010. Disponível em: https://ww2.ibge.gov.br/home/estatistica/populacao/censo2010/default.shtm.

LIMA, Maria Amélia X. C. O fazer institucionalizado: o cotidiano do asilamento. Dissertação (Mestrado) - Pontifícia Universidade Católica de São Paulo, São Paulo, 2005.

MACHADO, Evelcy Monteiro. A pedagogia social: diálogos e fronteiras com a educação não formal e educação sócio-comunitária. Revista de Ciências da Educação, v. 18, p. 99$122,2008$.

MDS - MINISTÉRIO DO DESENVOLVIMENTO SOCIAL. Política nacional de assistência social. Brasília, 2004.

MINAYO, Maria Cecília de S. O desafio do conhecimento: pesquisa qualitativa em saúde. São Paulo: Hucitec, 2007.

NERI, Anita Liberalesso; YASSUDA, Mônica Sanches; CACHIONI, Meire. O que a psicologia tem a oferecer ao estudo e à intervenção no campo do envelhecimento no Brasil, hoje. In: (Orgs.). Velhice bem-sucedida: aspectos afetivos e cognitivos. Campinas: Papirus, 2004, p. 13-27.

PINO, Angel S. A psicologia concreta de Vigotski: implicações para a educação. In: PLACCO, Vera Maria N. S. (Org.). Psicologia e educação. São Paulo: Cortez, 2002.

ROMANS, Mercè; PETRUS, Antoni; TRILLA, Jaume. Profissão: educador social. Porto Alegre: Artmed, 2003. 
SEDS - SECRETARIA ESPECIAL DO DESENVOLVIMENTO SOCIAL. Assistência social. 2015. Disponível em: < http://mds.gov.br/assistencia-social-suas $>$.

SILVA, Rerlen Ricardo. Projeto político-pedagógico: articulações com aspectos culturais locais e educação do campo na Escola Agrícola Municipal Carlos Heins Funke - Joinville/ SC. Dissertação (Mestrado) - Universidade da Região de Joinville, Joinville, 2015.

SILVA, Roberto; SOUZA NETO, João Clemente; MOURA, Rogério Adolfo de. Pedagogia social. São Paulo: Expressão e Arte, 2009, v. 1.

SPOSATI, Aldaíza. O primeiro ano do Sistema Único de Assistência Social. Revista Serviço Social e Sociedade, v. 87, p. 96-122, 2006.

VIGOTSKI, L. S. A construção do pensamento e da linguagem, 2. ed. São Paulo: Martins Fontes, 2009.

WELLER, Wivian. Grupos de discussão: aportes teóricos e metodológicos. In:

PFAFF, Nicolle (Orgs.). Metodologias da pesquisa qualitativa em educação - teoria e prática. Petrópolis: Vozes, 2013, p. 54-66.

\section{Dados OS Autores:}

\section{Jane Mery Richter Voigt}

Pós-Doutora pela Universidade do Minho. Portugal. Doutora em Educação pela Pontifícia Universidade Católica de São Paulo. Joinville/ SC - Brasil.

E-mail: jane-mery@univille.br

\section{Leandro Campos Barrocas}

Mestre em Educação pela Universidade da Região de Joinville. Joinville/SC - Brasil. Especialista em Direito e Gestão Empresarial pela Faculdade Cenecista de Joinville. Joinville/ $\mathrm{SC}-$ Brasil.

E-mail: leandro@barrocas.adv.br

\section{Silvia Sell Duarte Pillotto}

Pós-Doutora pela Universidade do Minho (Portugal). Doutora em Engenharia de Produção pela Universidade Federal de Santa Catarina. Professora do Programa de Pós-Graduação em Educação da Universidade da Região de Joinville. Joinville/ SC - Brasil.

E-mail: pillotto0@gmail.com

Submetido em: 1-12-2017

Aceito em: 16-10-2019 